\title{
Comparison Between the Effects of Alfentanil, Fentanyl and Sufentanil on Hemodynamic Indices During Rapid Sequence Intubation in the Emergency Department
}

\author{
Mahboob Pouraghaei ${ }^{1}$; Payman Moharamzadeh ${ }^{1}$; Hassan Soleimanpour ${ }^{2, *}$; Farzad \\ Rahmani ${ }^{1}$; Saeid Safari ${ }^{3}$; Ata Mahmoodpoor ${ }^{4}$; Hanieh Ebrahimi Bakhtavar ${ }^{5}$; Robab \\ Mehdizadeh Esfanjani ${ }^{6}$ \\ ${ }^{1}$ Anesthesiology Research Team, Department of Anesthesiology, Tabriz University of Medical Sciences, Tabriz, Iran \\ ${ }_{3}^{2}$ Cardiovascular Research Center, Tabriz University of Medical Sciences, Tabriz, Iran \\ ${ }^{3}$ Anesthesiology and Critical Care Department, Iran University of Medical Sciences, Tehran, Iran \\ ${ }_{5}^{4}$ Anesthesiology and Critical Care Department, Tabriz University of Medical Sciences, Tabriz, Iran \\ ${ }_{5}^{5}$ Students Research Committee, Tabriz University of Medical Sciences, Tabriz, Iran \\ ${ }^{6}$ Neurosciences Research Center, Tabriz University of Medical Sciences, Tabriz, Iran \\ ${ }^{*}$ Corresponding author: Hassan Soleimanpour, Cardiovascular Research Center, Tabriz University of Medical Sciences, Tabriz, Iran. Tel: +98-9141164134, Fax: +98-4113352078, E-mail: \\ soleimanpourh@tbzmed.ac.ir
}

Received: September 3, 2013; Revised: September 26, 2013; Accepted: October 15, 2013

Background: Laryngoscopy and tracheal intubation lead to the alteration of hemodynamic parameters, including blood pressure and heart rate, in traumatic patients who sustain rapid sequence intubation (RSI). Various drugs such as fentanyl, alfentanil and sufentanil have been used to modify these hemodynamic responses.

Objectives: The aim of the present study is to compare the effects of fentanyl, sufentanil and alfentanil in trauma patients who require RSI in the emergency department (ED).

Patients and Methods: This was a randomized double-blinded study conducted on 90 patients (18-65 years old, ASA I, II), who needed intubation following trauma. The patients were randomly divided into three groups, Group I, Group II and Group III, who have received alfentanil, fentanyl and sufentanil, respectively. Heart rate, blood pressure, saturation of peripheral oxygen and end-tidal carbon dioxide were measured 5 minutes before and 3, 5 and 10 minutes after intubation, respectively. The changes of the hemodynamic parameters were compared in between groups. Data were analyzed by One-way ANOVA, General Linear Model Repeated Measure and Mauchly's Sphericity Test. A P $<0.05$ was considered statistically significant.

Results: There was no significant statistical difference among groups with respect to hemodynamic parameters.

Conclusions: Alfentanil, fentanyl and sufentanil can be used safely as premedication drugs for trauma patients who need intubation.

Keywords: Intubation; Emergency Department; Hemodynamic Indices; Alfentanil; Fentanyl; Sufentanil

\section{Background}

In the trauma patient, the priority is airway management (1). The most common method used for tracheal tube insertion in the ED is RSI or direct laryngoscopy. The RSI has been accepted as the most advisable approach for patients who need intubation (2). Also, RSI is the principle of modern airway management in the ED for achieving tracheal tube insertion. However, it is necessary to prescribe simultaneously a potent hypnotic, analgesic and muscle relaxant (2-4). Intubation and direct laryngoscopy can increase heart rate (HR) and blood pressure (BP), a phenomenon described as pressor response (5-7). Tachycardia and hypertension lead to an imbalance between the supply and demand of oxygen to the myocardial muscle, which can lead to ischemia, myocardial infarction and cardiac failure (8). Thus, undesirable hemodynamic responses to intubation should be attenuated via different intubation techniques or pharmacological agents. The laryngoscopic stimulation of the oropharyngolaryngeal structures and the distention of the supraglottic tissues may play an important role in hemodynamic stress response (9). This pressor response is transient, occurring 30 seconds after intubation and lasting for less than 10 minutes. Opioids have been used to block the pressor response (10).

Synthetic opioids, such as alfentanil, sufentanil and fentanyl, are frequently used for adult intubation (6). Com-

Implication for health policy/practice/research/medical education:

Laryngoscopy and tracheal intubation lead to the alteration of hemodynamic parameters including blood pressure and heart rate in traumatic patients who undergo rapid sequence intubation. We tried to compare the changes of hemodynamic parameters following intubation in three opioids: fentanyl, alfentanil and sufentanil. The results indicated that there was no statistically significant difference among these changes and the investigated drugs.

Copyright @ 2014, Iranian Society of Regional Anesthesia and Pain Medicine(ISRAPM); Published by KowsarCorp. This is an open-access article distributed under the terms of the Creative Commons Attribution License, which permits unrestricted use, distribution, and reproduction in any medium, provided the original work is properly cited. 
parisons between the numerous effects of these drugs in children have been conducted in various studies, yet for adult patients the data are only limited.

\section{Objectives}

The aim of the present study was to compare the effects of these drugs on the variation of hemodynamic parameters in intubated traumatic patients.

\section{Patients and Methods}

This study was a randomized double-blinded design and it was been carried out during 9 months (from October 2012 to June 2013) in the ED of Imam Reza Research and Training Hospital, Tabriz, East Azerbaijan Province, Iran, with an annual admission rate of 110000 patients (11). Due to the lack of sufficient studies in this field or due to the lack of similar studies in an emergency department, our study was firstly done in the form of a pilot study on 90 patients (three groups of 30 patients). The collection of samples was done from 8 AM. to 6 PM, 7 days a week.

In conformity with the inclusion criteria of the study, the sample included only the trauma patients referred to Imam Reza Hospital, aged 18-65 years old, who had normal BP, needed emergency intubation and were classified as either ASA I or II patients.

The study excluded patients who needed crush intubation (unresponsive patient or near death), were allergic to lidocaine, were suspect of a difficult intubation based on the physician's clinical judgment (facial anomaly, large mustache, micrognathia, ear and hand anomaly, large incisor teeth) (11), history of malignant hyperthermia or pseudocholinesterase deficiency, pregnancy, multiple failed intubation attempts and intubation maneuver lasting for more than 20 seconds.

This study has received the approval of the Ethics Committee of Tabriz University of Medical Sciences, with the number 2705 and it has also been registered by the Iranian Registry of Clinical Trials (IRCT) under the number of IRCT2012101011067N1. The patients were randomly divided into three groups, as follows:

The existing opioids (alfentanil, fentanyl and sufentanil) were labeled I, II, III in separate syringes prepared in advance (so that in each milliliter of solution in these syringes there existed similar effective drugs). The intubator doctor, who was unaware of the name of the drug, took a ball from a bag with 90 balls (30 balls with No.1, 30 balls with No.2 and 30 balls with No.3) and chose the related syringe based on the obtained balls to use while intubating. In this study, the doctor and the patient were unaware of the opioids' names, and all the drugs had been put in the intubation trolley in advance by the project responsible. For Group I, alfentanil $500 \mu \mathrm{g} / \mathrm{cc}$ (Janssen Pharmaceutical Company, Beers, Belgium) with a dosage of $20 \mu \mathrm{g} / \mathrm{kg}$ of body weight. In Group II, fentanyl
$50 \mu \mathrm{g} / \mathrm{cc}$ (Mylan Pharmaceutical Company, Saint Priest, France) with a dose of $2 \mu \mathrm{g} / \mathrm{kg}$. In Group III, sufentanil $5 \mu \mathrm{g} / \mathrm{cc}$ (Mylan Pharmaceutical Company, Saint Priest, France) with a dose of $0.2 \mu \mathrm{g} / \mathrm{kg}$.

All the patients were hydrated during pre-intubation with Ringer serum $10 \mathrm{~mL} / \mathrm{kg}$. After preoxygenation and premedication with lidocaine $1.5 \mathrm{mg} / \mathrm{kg}$ and alfentanil $(20 \mu \mathrm{g} / \mathrm{kg})$, fentanyl $(2 \mu \mathrm{g} / \mathrm{kg})$, and sufentanil $(0.2 \mu \mathrm{g} / \mathrm{kg})$ based on the group, respectively, anesthesia was induced with etomidate $(0.3 \mathrm{mg} / \mathrm{kg})$ and atracurium $0.2 \mathrm{mg} / \mathrm{kg}$ (defasciculating dose). Muscle relaxation was achieved by using succinylcholine $(1 \mathrm{mg} / \mathrm{kg})$, administered via a peripheral cannula. After 1 minute from the administration of succinylcholine, the trachea was intubated with an appropriate size orotracheal tube.

Cardiac monitoring was connected for all patients by a monitoring device before intubation (Saadat Novin S1800, Pooyandegan Rah Saadat Corporation, Tehran, Iran). $\mathrm{HR}, \mathrm{BP}$ and the $\mathrm{SpO}_{2}$ were registered by the mentioned device and also, the rate of $\mathrm{ETCO}_{2}(12)$ was measured by another monitoring device (NICO 7300, Novametrix Corporation, Wallingford, USA). Five minutes after registering these values, intubation was performed, and in minutes 3, 5 and 10 after intubation, the mentioned indices were registered again. Figure 1 reveals a flow chart of the measurements of these parameters. For data analysis, the SPSS version 17.01 (SPSS Inc., Chicago, Illinois) was used. The normal distribution of the data was surveyed using the Kolmogorov-Smirnoff test.

For the statistical comparison of the hemodynamic parameters among the three groups, One-way ANOVA Test was used. The changes of the hemodynamic parameters in each group were studied using the General Linear Model Repeated Measure and Mauchly's Test of Sphericity. In all cases, a $\mathrm{P}<0.05$ was considered statistically significant.

\section{Results}

A total of 90 patients (71 men and 19 women) participated in this study. The average age of the study group was $41.73 \pm 15.3$. From the statistical view point, there was no significant difference between the three groups considering age $(P=0.116)$ and sex $(P=0.282)$. Table 1 shows sex, ASA class and mean age distribution in all groups. There was no significant statistical difference among groups concerning HR $(\mathrm{P}=0.319)$, Systolic $\mathrm{BP}(\mathrm{SBP})(\mathrm{P}=0.76)$, $\mathrm{SpO}_{2}(\mathrm{P}=0.336), \mathrm{ETCO}_{2}(\mathrm{P}=0.111)$ and Diastolic $\mathrm{BP}(\mathrm{DBP})(\mathrm{P}$ $=0.24)$ in the 5 minutes before and the 3,5 and 10 minutes after intubation (Table 2).

There was a statistically significant difference within each group during the intubation phase concerning BP (both systolic and diastolic), but with a variation no greater than $\pm 20 \%$. The repetitive analysis of the variables concerning this study, in relation to the administration of opioids is shown in Figures 2 and $3(\mathrm{P}<0.001)$. 


\section{Appendix: Patients Flowchart}

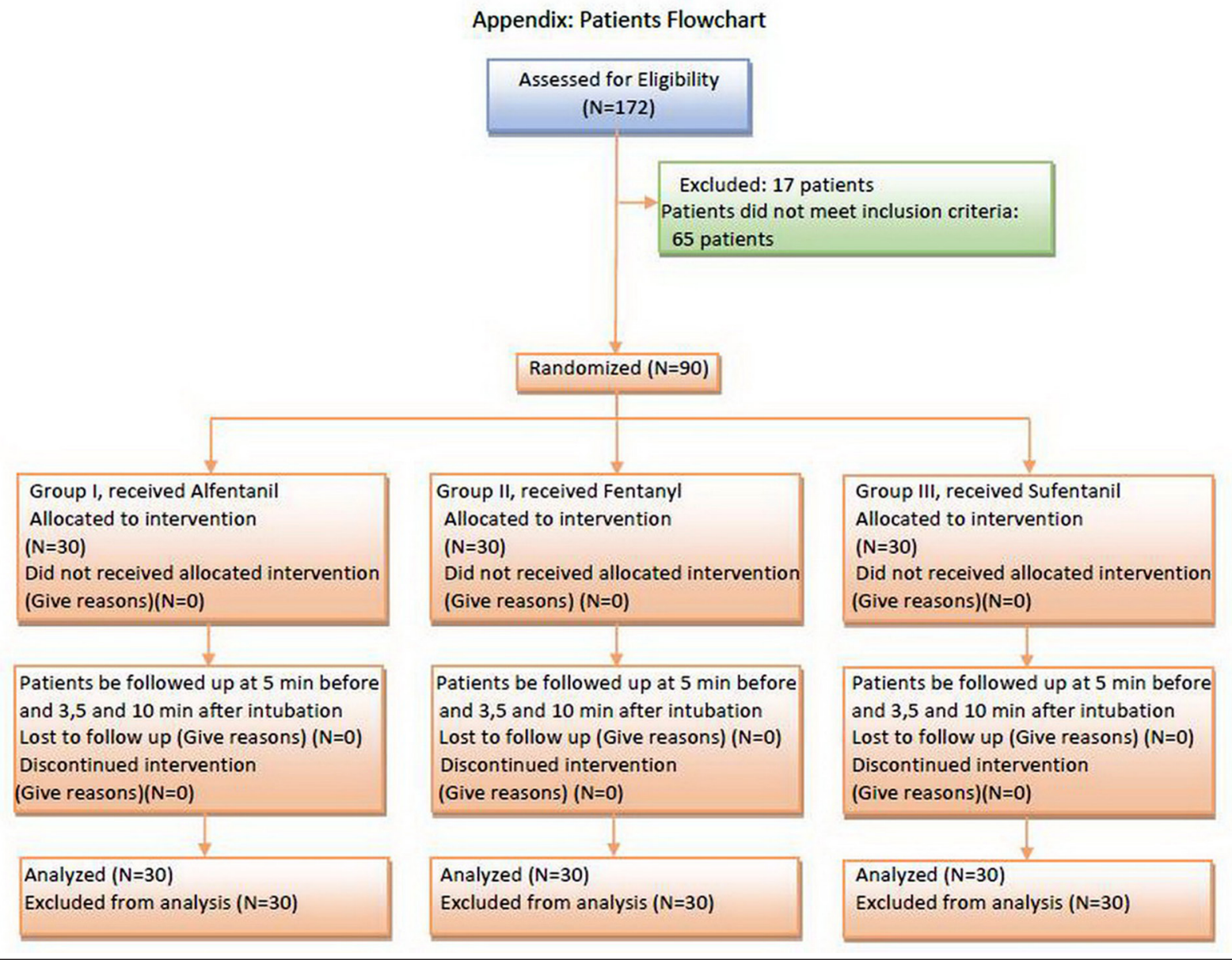

Figure 1. Flow Chart of the Study

Table 1. Patients' Characteristics

\begin{tabular}{llll}
\hline Variables & Group I (Alfentanil) $(\mathbf{N}=\mathbf{3 0})$ & Group II $($ Fentanyl $)(\mathbf{N}=\mathbf{3 0})$ & Group III $($ Sufentanil $)(\mathbf{N}=\mathbf{3 0})$ \\
\hline Age, Mean \pm SD, $\mathbf{y}$ & $37.06 \pm 14.49$ & $44.43 \pm 16.08$ & $43.96 \pm 14.22$ \\
Sex, Female/Male & $4 / 26$ & $4 / 26$ & $9 / 21$ \\
ASA Class I & 25 & 22 & 23 \\
ASA Class II & 5 & 8 & 7 \\
\hline
\end{tabular}

\section{Discussion}

The use of various drugs (such as hypnotics, opiates and muscle relaxants) during tracheal intubation may lead to the alteration of hemodynamic parameters in patents. In most situations, RSI is the most common approach to control the emergency airway which is used by Emergen- cy Medicine (13-15). Based on the previous evidences, the hemodynamic parameters, before and after intubation by RSI, should not record a variation greater than $\pm 20 \%$. The drugs used in our study (alfentanil, fentanyl, sufentanil) did not modify the hemodynamic parameters more than $20 \%(16-24)$. 
Table 2. Pre-Intubation and Post-Intubation Records of SBP and DBP, $\mathrm{HR}, \mathrm{SpO}_{2}$ and $\mathrm{ETCO}_{2}$

\begin{tabular}{|c|c|c|c|}
\hline Variables & Group I (Alfentanil) $(\mathrm{N}=\mathbf{3 0})$ & Group II (Fentanyl) $(\mathbf{N}=\mathbf{3 0})$ & Group III (Sufentanil) $(\mathrm{N}=\mathbf{3 0})$ \\
\hline \multicolumn{4}{|c|}{$\begin{array}{l}5 \text { Minutes Before Intuba- } \\
\text { tion, mean } \pm \text { SD }\end{array}$} \\
\hline $\mathrm{HR}^{\mathrm{a}}$ & $84.73 \pm 21.33$ & $86.36 \pm 19.54$ & $88.43 \pm 18.03$ \\
\hline $\mathrm{SBP}^{\mathrm{a}}$ & $137.76 \pm 28.50$ & $135.90 \pm 25.49$ & $124.83 \pm 21.84$ \\
\hline $\mathrm{DBP}^{\mathrm{a}}$ & $82.06 \pm 17.56$ & $86.46 \pm 14.16$ & $80.66 \pm 17.86$ \\
\hline $\mathrm{SpO}_{2}{ }^{\mathrm{a}}$ & $83.36 \pm 14.81$ & $89.20 \pm 7.65$ & $88.90 \pm 9.16$ \\
\hline $\mathrm{ETCO}_{2}{ }^{\mathrm{a}}$ & $37.66 \pm 6.88$ & $36.06 \pm 7.39$ & $34.56 \pm 5.81$ \\
\hline \multicolumn{4}{|c|}{$\begin{array}{l}3 \text { Minutes After Intubation, } \\
\text { mean } \pm \text { SD }\end{array}$} \\
\hline HR & $83.56 \pm 20.67$ & $86.46 \pm 19.12$ & $89.43 \pm 17.98$ \\
\hline SBP & $137.40 \pm 29.93$ & $134.13 \pm 25.62$ & $122.20 \pm 21.43$ \\
\hline DBP & $78.76 \pm 16.02$ & $84.76 \pm 13.80$ & $78.56 \pm 15.35$ \\
\hline $\mathrm{SpO}_{2}$ & $95.86 \pm 4.65$ & $96.93 \pm 2.93$ & $95.70 \pm 4.94$ \\
\hline $\mathrm{ETCO}_{2}$ & $35.50 \pm 4.85$ & $34.63 \pm 5.36$ & $32.63 \pm 4.76$ \\
\hline \multicolumn{4}{|c|}{$\begin{array}{l}5 \text { Minutes After Intubation, } \\
\text { mean } \pm \text { SD }\end{array}$} \\
\hline HR & $79.06 \pm 18.91$ & $84.80 \pm 15.75$ & $88.46 \pm 18.03$ \\
\hline SBP & $131.00 \pm 28.75$ & $132.70 \pm 26.39$ & $120.83 \pm 20.75$ \\
\hline DBP & $77.10 \pm 15.60$ & $82.13 \pm 14.66$ & $78.63 \pm 16.85$ \\
\hline $\mathrm{SpO}_{2}$ & $97.40 \pm 3.90$ & $97.13 \pm 3.14$ & $97.26 \pm 3.45$ \\
\hline $\mathrm{ETCO}_{2}$ & $34.00 \pm 4.27$ & $33.46 \pm 4.23$ & $32.03 \pm 4.20$ \\
\hline \multicolumn{4}{|c|}{$\begin{array}{l}10 \text { Minutes After Intuba- } \\
\text { tion, mean } \pm \text { SD }\end{array}$} \\
\hline HR & $78.46 \pm 19.05$ & $83.70 \pm 16.09$ & $87.73 \pm 17.99$ \\
\hline SBP & $130.23 \pm 25.51$ & $133.70 \pm 25.25$ & $119.23 \pm 21.76$ \\
\hline DBP & $77.96 \pm 12.62$ & $83.03 \pm 13.80$ & $76.86 \pm 14.24$ \\
\hline $\mathrm{SpO}_{2}$ & $97.86 \pm 3.54$ & $97.63 \pm 3.06$ & $98.20 \pm 2.67$ \\
\hline $\mathrm{ETCO}_{2}$ & $33.36 \pm 3.36$ & $33.50 \pm 4.40$ & $32.03 \pm 3.93$ \\
\hline
\end{tabular}

a Abbreviations: DBP, diastolic blood pressure; $\mathrm{ETCO}_{2}$, end-tidal carbon dioxide; HR, heart rate; SBP, systolic lood pressure; $\mathrm{SpO}_{2}$, saturation of peripheral oxygen.

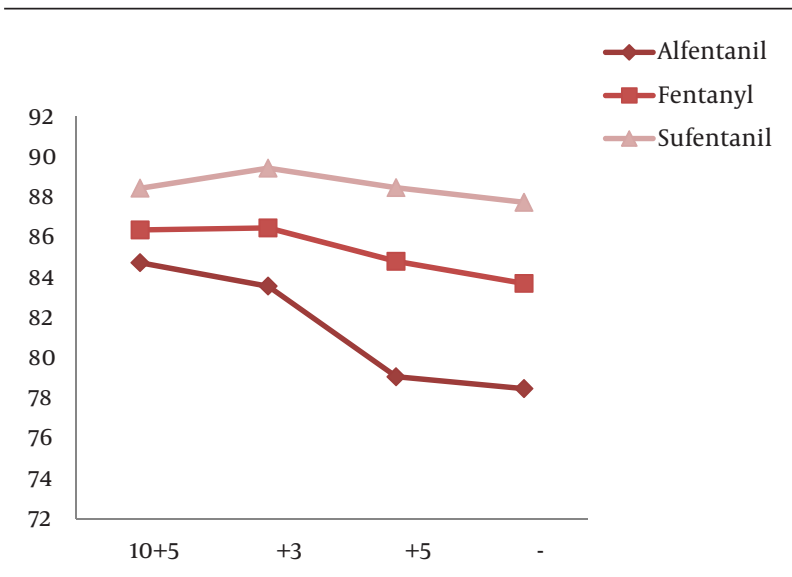

HR

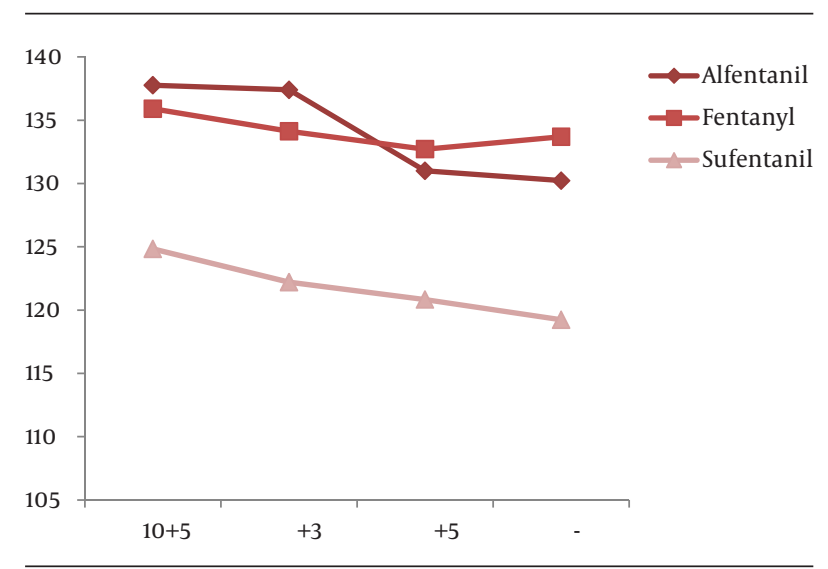

Figure 3. Changes in SBP during Repeated Measuring $(\mathrm{P}<0.001)$

Various studies have been conducted to investigate the hemodynamic response following intubation
Figure 2. Changes in HR during Repeated Measuring $(\mathrm{P}<0.001)$ 
and the hemodynamic parameters changes due to numerous inducing agents. However, all these reports have been conducted mainly on infant-age patients, or in the operating room, in elective conditions. The study of Mireskandari et al. on 80 children aged 1 to 6 years old concluded that fentanyl, in comparison with sufentanil, alfentanil and remifentanil, ensures a superior hemodynamic stability (6). In this study, at three different stages i.e. base line (prior to opioid usage), before laryngoscopy and a minute after intubation, the hemodynamic responses were evaluated. However, in the repeated measuring following intubation, not all parameters were measured. Iftikhar et al., in their study on 60 patients, have concluded that oral gabapentin before intubation leads to the reduction of the stressor response in elective surgeries (8). Safavi et al. in their study on 60 patients, have concluded that, in case of sufficient time for injecting and onset of the effect of opioids before intubation, there is no difference between intravenous pethidine and intravenous sufentanil, in controlling the stressor response following intubation (25). Xue et al. investigated 93 children aged 3 to 9 years old, and have come to conclusion that the injection of sufentanil during intubation leads to a better control of the stressor response following intubation. In this study, various doses of the same medication were administered. In contrast, different agents were used in our study (26). Ko et al. in their study on 90 patients with age greater than 65 years old, have concluded that pretreatment with remifentanil, rather than fentanyl, is more effective in suppressing cardiovascular responses due to endotracheal intubation. However, in our study, remifentanil was not utilized and its comparison with other opioids is suggested (27).

Our results are different from the one reported in the studies of Mireskandari et al. (6), Ko et al. (27) and Xue et al. (26) studies. Our study has been focused on the hemodynamic changes following the intubation of traumatic patients with ASA classification I and II who have normal blood pressure. Since no statistically significant difference was observed in the hemodynamic parameters (SBP, DBP, $\mathrm{HR}, \mathrm{SpO}_{2}$, and $\mathrm{ETCO}_{2}$ ) of patients, we can use these opioid agents safely in the RSI. However, in the reference books on emergency medicine, fentanyl has been introduced as an opioid in RSI.

According to the results of our study, these three opioids (fentanyl, alfentanil and sufentanil) can be used for intubating trauma patients in the emergency department without significant differences.

\subsection{Limitations}

As time-to-peak effect of these opioids is different, an aspect that has not been taken into consideration in the present study, future investigations should be designed to also assess this different effect. Due to the sample collection, which was done at specific moments of the day
(8:00 AM - 6:00 PM), we were limited to include only patients who needed intubation during this time interval. Other limitations of this study were the sample size, which was too small, and also the fact that data were collected in a single center.

\section{Acknowledgements}

The authors are grateful to all the health personnel and patients who participated in the study, in addition to the data collectors, supervisors and administrative staff of the Emergency Department of Imam Reza Hospital. Special thanks to Anesthesiology Research Team, Department of Anesthesiology, Tabriz University of Medical Sciences, Tabriz, Iran. This article was written based on dataset of Hanieh Ebrahimi Bakhtavar's specialty thesis entitled "Comparison between the Effects of Alfentanil, Fentanyl and Sufentanilon on hemodynamic indices during Rapid Sequence Intubation in the Emergency Department", registered in Tabriz University of Medical Sciences (No:90.3-2.6) and was presented in Wednesday, July 3, 2013. We would also like to express our sincere appreciation to Mrs. Farnoosh Rahmani for scientific editing of this manuscript.

\section{Authors' contributions}

All authors have read and approved the manuscript. Mahboob Pouraghaei, Payman Moharamzadeh, Hassan Soleimanpour, Farzad Rahmani and Hanieh Ebrahimi Bakhtavar performed the data collection, literature review, and drafting of the manuscript. Saeid Safari, Ata Mahmoodpoor and Robab Mehdizadeh Esfanjani undertook the major parts of the study design and performed the statistical analysis.

\section{Financial Disclosure}

The authors declare they have no financial disclosure.

\section{Funding/ Support}

This article is not supported by any funding organization. There is no sponsor for this work.

\section{References}

1. Soleimanpour H, Tabrizi JS, Farnam A, Nikakhtar M, Mokhtarpour M, Golzari SE, et al. Attitudes of emergency medicine physicians towards family presence during resuscitation. Resuscitation. 2013;84(12):e149-50.

2. Marx J, Hockberger R, Walls R. Emergency Medicine: Concepts and Clinical Practice.: Elsevier Health Sciences; 2009.

3. Sedighinejad A, Naderi Nabi B, Haghighi M, Imantalab V, Hadadi S, Erfani Sayar R, et al. Propofol is Effective to Depress FentanylInduced Cough during Induction of Anesthesia. Anesth Pain Med. 2013;2(4):170-3.

4. Soleimanpour H, Gholipouri C, Panahi JR, Afhami MR, Ghafouri RR, Golzari SE, et al. Role of anesthesiology curriculum in improving bag-mask ventilation and intubation success rates of emergency medicine residents: a prospective descriptive study. BMC Emerg Med. 2011;11:8.

5. Akan M, Oztekin S. Endotracheal Intubation Without Neuromus- 
cular Blocking Agents: Is It a Good and Safe Option? Anesth Pain Med. 2012;1(4):267-8.

6. Mireskandari SM, Abulahrar N, Darabi ME, Rahimi I, Haji-Mohamadi F, Movafegh A. Comparison of the effect of fentanyl, sufentanil, alfentanil and remifentanil on cardiovascular response to tracheal intubation in children. Iran J Pediatr. 2011;21(2):173-80.

7. Rahimi Panahi J, Mahmoodpoor A, Rajaei Ghafouri R. Digital intubation training in residency program, as an alternative method in airway management. Pakistan J Med Sci. 2011;27(2).

8. Iftikhar T, Taqi A, Sibtain A, Anjum S, Awan I. Oral gabapentin reduces hemodynamic response to direct lar yngoscopy and tracheal intubation. Anesthesia, Pain \& Intensive Care. 2011;15:17-21.

9. Akhlagh SH, Vaziri MT, Masoumi T, Anbardan SJ. Hemodynamic response to tracheal intubation via direct laryngoscopy and intubating laryngeal mask airway (ILMA) in patients undergoing coronary artery bypass graft (CABG). Middle East J Anesthesiol. 2011;21(1):99-103.

10. Gupta A, Wakhloo R, Gupta V, Mehta A, Kapoor B. Comparison of Esmolol and Lignocaine for Attenuation of Cardiovascular Stress Response to Laryngoscopy and Endotracheal Intubation. JK science. 2009;11(2).

11. Soleimanpour H, Gholipouri C, Salarilak S, Raoufi P, Vahidi RG, Rouhi AJ, et al. Emergency department patient satisfaction survey in Imam Reza Hospital, Tabriz, Iran. Int J Emerg Med. 2011;4:2.

12. Soleimanpour H, Taghizadieh A, Niafar M, Rahmani F, Golzari SE, Esfanjani RM. Predictive value of capnography for suspected diabetic ketoacidosis in the emergency department. West JEmerg Med. 2013;14(6):590-4.

13. Hopson LR, Schwartz RB. Pharmacologic adjuncts to intubation. In: Roberts JR, Hedges JR, editors. Clinical procedures in emergencymedicine. 5th ed. Elsevier Health Sciences; 2009.

14. Soleimanpour H, Khoshnudi F, Movaghar MH, Ziapour B. Improvement of decerebrate status in a hanged child following emergent tracheostomy. Pak J Biol Sci. 2010;13(23):1164-5.

15. Soleimanpour H, Shams Vahdati S, Mahmoodpoor A, Rahimi Panahi J, Afhami MR, Pouraghaei M, et al. Modified cricothyroidotomy in skill laboratory.J Cardiovasc Thorac Res. 2012;4(3):73-6.

16. Aghamohammadi D, Eydi M, Hosseinzadeh H, Amiri Rahimi M, Ej Golzari S. Assessment of Mini-dose Succinylcholine Effect on
FacilitatingLaryngeal Mask Airway Insertion. J Cardiovasc Thorac Res. 2013;5(1):17-21.

17. Bilotta F, Rosa G. Remifentanil or Alfentanil for Endotracheal Intubation. Anesth Pain Med. 2012;1(4):277-8.

18. Golzari SE, Khan ZH, Ghabili K, Hosseinzadeh H, Soleimanpour H, Azarfarin R, et al. Contributions of Medieval Islamic physicians to the history of tracheostomy. Anesth Analg. 2013;116(5):1123-32.

19. Hanci V. Tracheal Intubation Without Use of Muscle Relaxants: Comparison of Remifentanil and Alfentanil. Anesth Pain Med. 2012;1(3):210-1.

20. Hassani V, Movassaghi G, Goodarzi V, Safari S. Comparison of fentanyl and fentanyl plus lidocaine on attenuation of hemodynamic responses to tracheal intubation in controlled hypertensive patients undergoing general anesthesia. Anesth Pain Med. 2013;2(3):115-8.

21. Imani F, Alebouyeh MR, Taghipour-Anvari Z, Faiz SHR. Use of Remifentanil and Alfentanil in Endotracheal Intubation: A Comparative Study. Anesth Pain Med. 2011;1(2):61-65.

22. Mahmoodpoor A, Soleimanpour H, Nia KS, Panahi JR, Afhami M, Golzari SE, et al. Sensitivity of palm print, modified mallampati score and 3-3-2 rule in prediction of difficult intubation. Int J Prev Med. 2013;4(9):1063-9.

23. Soleimanpour H, Gholipouri C, Golzari SEJ, Rahmani F, Sabahi M, Mottram AR, et al. Capnography in the Emergency Department. Emergency Med. 2012;2:e123

24. Soleimanpour H, Golzari SEJ, Rahmani F, Mokhtarpour M. Inadvertent Arterial Puncture During Central Venous Catheter Insertion.J Clin Analytic Med. 2013;[In press].

25. Safavi M, Honarmand A. Attenuation of cardiovascular responses to laryngoscopy and tracheal intubation-intravenous sufentanil vs pethidine. Middle East J Anesthesiol. 2008;19(6):1349-59.

26. Xue FS, Liu KP, Liu Y, Xu YC, Liao X, Zhang GH, et al. Assessment of small-dose fentanyl and sufentanil blunting the cardiovascular responses to laryngoscopy and intubation in children. Paediatr Anaesth. 2007;17(6):568-74.

27. Ko BJ, Oh JN, Lee JH, Choi SR, Lee SC, Chung CJ. Comparison of ef fects of fentanyl and remifentanil on hemodynamic response to endotracheal intubation and myoclonus in elderly patients with etomidate induction. Korean J Anesthesiol. 2013;64(1):12-8. 